\title{
ANALISIS STRUKTUR PASAR MALAI PANDANWANGI DI DESA TEGALLEGA KECAMATAN WARUNGKONDANG KABUPATEN CIANJUR
}

\author{
Oleh : \\ Farida Kuncana *) \\ Rosda Malia **)
}

\begin{abstract}
Abstrak
Permintaan lembaga pemasaran terhadap malai Pandanwangi di Desa Tegallega, mencapai 162 ton / tahun. Belum lagi permintaan-permintaan konsumen dari luar daerah terhadap beras Pandanwangi kepada lembaga pemasaran terus meningkat setiap tahunnya. Perubahan jumlah permintaan lembaga pemasaran terhadap malai Pandanwangi, merupakan salah satu hal penting yang perlu dianalisis dalam pemasaran malai ini. Struktur pasar merupakan organisasi dari suatu pasar yang dapat mempengaruhi keadaan persaingan dan penentuan harga pasar. Pengukuran struktur pasar penting diketahui karena pasar yang tidak kompetitif cenderung berlaku tidak adil. Penelitian dilakukan di Desa Tegallega Kecamatan Warungkondang Kabupaten Cianjur selama Bulan Maret 2018 dengan tujuan untuk 1) Mengetahui dinamika harga malai Pandanwangi di Desa Tegallega Kecamatan Warungkondang Kabupaten Cianjur, 2) Mengetahui penawaran dan permintaan malai Pandanwangi di Desa Tegallega Kecamatan Warungkondang Kabupaten Cianjur, 3) Mengetahui struktur pasar malai Pandanwangi di Desa Tegallega Kecamatan Warungkondang Kabupaten Cianjur. Penelitian ini menggunakan teknik purposive sampling dalam penentuan tempat dan responden. Hasil penelitian ini menunjukkan bahwa dinamika harga malai Pandanwangi pada Tahun 2013 - 2017 tidak mengalami perubahan, yaitu berkisar Rp. 5.000,00 - Rp. 5.500,00. Sedangkan penawaran dalam 5 tahun terakhir, jumlah malai yang dibeli lembaga pemasaran berkisar pada $162.000 \mathrm{~kg}$ per tahun dan permintaan beras dalam 5 tahun terakhir berkisar pada $72.900 \mathrm{~kg}$ per tahun. Pada struktur pasar malai Pandanwangi di Desa Tegallega berdasarkan data hasil analisis menunjukkan pada pasar oligopsoni.
\end{abstract}

Kata Kunci : Malai Pandanwangi, dinamika harga, penawaran, permintaan, struktur pasar.

\begin{abstract}
Demand from marketing institutions for Pandanwangi panicle in Tegallega Village alone, reached 162 tons / year. Not to mention the demand of consumers for Pandanwangi rice from outside the region to the marketing institutions continue to increase every year. Changes in the amount that marketing institutions to malay Pandanwangi is one of the important things which need to be analyzed in the marketing of Pandanwangi malay. The market structure is the organization of a market that can affect the state of competition and market pricing. The measurement of market structure is important because the uncompetitive market tends to be unfair. The research was conducted in Tegallega Village, Warungkondang Sub-district, Cianjur Regency during March 2018 with the aim of 1) To know the price dynamics of Pandanwangi malay in Tegallega Village, Warungkondang Sub-district of Cianjur Regency, 2) To know the supply and demand of Pandanwangi malay in Tegallega Village, Warungkondang Sub-district, Cianjur Regency, 3) To know market structure of Pandanwangi malay in Tegallega Village, Warungkondang District, Cianjur Regency. This research uses purposive sampling technique in determining place and respondent. The results of this research indicates that the price dynamics of Pandanwangi malay in $2013-2017$ did not change, which is around Rp. 5.000,00 - Rp. 5.500,00. While demand in the last 5 years, the number of panicles purchased
\end{abstract}


by marketing institutions ranges from 162,000 kg per year and rice demand in the last 5 years ranges from $72,900 \mathrm{~kg}$ per year. In the structure of malay Pandanwangi in Tegallega Village based on data analysis result shows on oligopsoni market.

Keywords: Pandanwangi malay, price dynamics, supply, demand, market structure.

* Alumni Faster UNSUR

** Dosen Faster UNSUR 


\section{PENDAHULUAN}

Padi merupakan komoditas strategis yang bernilai sosial, politik dan ekonomi karena merupakan bahan makanan pokok penduduk Indonesia. Bagi sebagian besar masyarakat Indonesia, selain berfungsi sebagai makanan pokok juga merupakan sebagai mata pencaharian. Oleh karena itu, upaya peningkatan produksi komoditas pangan ini mendapat prioritas yang tinggi (Hadikusumah, KH. 2015).

Satu jenis padi varietas unggul lokal yang tumbuh dan berkembang di daerah Cianjur adalah Padi Pandanwangi. Beras Pandanwangi memiliki nilai jual yang tinggi, karena memiliki rasa yang manis, pulen dan wangi. Permintaannya tinggi terutama dari kalangan menengah ke atas.

Desa Tegallega Kecamatan Warungkondang merupakan desa penghasil beras pandanwangi. Permintaan lembaga pemasaran terhadap malai Pandanwangi di Desa Tegallega saja mencapai $162.000 \mathrm{~kg} /$ tahun. Permintaan lembaga pemasaran kepada produsen padi Pandanwangi di Desa Tegallega terus meningkat setiap tahunnya.

Perubahan jumlah yang diminta lembaga pemasaran terhadap produsen penting untuk dianalisis sebagai pemasaran hasil usahatani padi Pandanwangi. Pelaksanaan analisis tersebut bergantung pada tujuan analisis itu sendiri yang berupa pemecahan permasalahan di bidang pemasaran secara mikro maupun makro. Sementara itu, ada lima pendekatan yang dapat dilakukan untuk menganalisis permasalahan dalam pemasaran yaitu pendekatan komoditi, pendekatan kelembagaan atau institusi, pendekatan fungsional, pendekatan organisasi industri, pendekatan efisiensi pasar atau pendekatan analitis dan manajemen pemasaran (Anindita $\mathrm{R}$ dan Baladina N, 2017).

Salah satu pendekatan adalah struktur pasar, pendekatan ini dapat mempengaruhi tingkah laku dan menghasilkan suatu penampilan pasar.
Struktur pasar membahas tentang bagaimana suatu pasar terorganisasi dengan didasarkan pada karakteristik yang menentukan hubungan antar penjual dengan pembeli serta antara pembeli dan penjual di pasar. Pengukuran struktur pasar penting diketahui karena pasar yang tidak kompetitif cenderung berlaku tidak adil (Saragih, 2014).

Menurut Suryana A (2012) menyatakan bahwa struktur pasar gabah dan beras di Indonesia masih belum efisien. Aviny at al. (2009) menyatakan bahwa struktur pasar menentukan perilaku para pelaku pasar yang pada akhirnya akan sangat mempengaruhi secara signifikan kinerja suatu industri. Sistem pemasaran yang tidak efisien akan merugikan petani padi Pandanwangi, sehingga dikhawatirkan eksistensi padi Pandanwangi akan memudar dan akhirnya mengalami penurunan produktivitas.

\section{Tujuan Penelitian}

Tujuan penelitian : (1) untuk mengetahui dinamika harga Malai Pandanwangi di Desa Tegallega Kecamatan Warungkondang Kabupaten Cianjur. (2) Untuk mengetahui penawaran dan permintaan Malai Pandanwangi di Desa Tegallega Kecamatan Warungkondang Kabupaten Cianjur. (3) Untuk mengetahui struktur pasar Malai Pandanwangi di Desa Tegallega Kecamatan Warungkondang Kabupaten Cianjur berada.

\section{METODE PENELITIAN}

\section{Tempat dan Waktu Penelitian}

Penelitian dilaksanakan di Desa Tegallega, Kecamatan Warungkondang. Pemilihan lokasi secara sengaja (purposive), karena Desa Tegallega penghasil malai Pandanwangi terbesar di Kecamatan Warungkondang. Penelitian dilakukan selama 1 bulan (Bulan Maret 2018).

\section{Teknik Pengumpulan Data}

Sugiyono (2011) menjelaskan bahwa pengumpulan data dapat dilakukan 
dalam berbagai setting, berbagai sumber dan berbagai cara. Menurut Lungan (2006), data primer dan data sekunder dibedakan berdasarkan cara memperolehnya. Penelitian ini menggunakan data primer dan data sekunder yang diperoleh melalui : observasi, wawancara dan kuisioner.

\section{Variabel Penelitian}

Variabel penelitian pada dasarnya adalah segala sesuatu yang berbentuk apa saja yang ditetapkan oleh peneliti untuk dipelajari sehingga diperoleh informasi tentang hal tersebut, kemudian ditarik kesimpulannya (Sugiyono, 2012). Variabel penelitian di dalam penelitian ini adalah sebagai berikut : a. dinamika harga, b. permintaan, c. penawaran dan d. struktur pasar.

\section{Metode Analisis Data}

Metode analisis data yang digunakan adalah dianalisis secara deskriptif dan kuantitatif. Hay dan Morris (2009) dalam Widia at al. (2015) menyatakan bahwa struktur pasar dianalisis secara deskriptif dan kuantitatif. Analisis struktur pasar secara deskriptif, yaitu dengan menjelaskan jumlah pelaku pasar dan hambatan keluar masuk pasar. Analisis struktur pasar secara kuantitatif yaitu dengan menghitung konsensentrasi rasio, market share dan nilai indeks Herfindhal.

\section{HASIL DAN PEMBAHASAN}

\section{Penelitian}

\section{Gambaran Umum Wilayah}

Desa Tegallega merupakan wilayah pembangunan utara Kecamatan Warungkondang Kabupaten Cianjur. Merupakan dataran tinggi yang terletak di kaki gunung Gede dengan topografi didominasi bergunung dan pegunungan, sehingga daerah ini mendapatkan pengairan yang cukup baik khususnya untuk irigasi persawahan serta keadaan iklim yang sangat mendukung bagi pertumbuhan dan perkembangan budidaya pertanian. Berbatasan wilayah sebelah utara adalah Desa Bunikasih, sebelah selatan adalah Desa Mekarwangi, sebelah barat adalah Kabupaten Bogor dan sebelah timur adalah Desa Bunisari. Luas wilayah Desa Tegallega yaitu 1000,350 ha.

\section{Umum Responden}

Responden penelitian ini berjumlah 13 orang, diantaranya : 6 orang pengurus kelompok tani, 5 orang lembaga pemasaran / tengkulak besar yang membeli malai Pandanwangi dari petani di Desa Tegallega dan seorang penyuluh sekaligus anggota BP3K Kecamatan Warungkondang serta aparat Kantor Desa Tegallega.

Semua responden berjenis kelamin laki laki. Hal ini dapat dipahami karena laki-laki, merupakan kepala keluarga sekaligus tulang punggung bagi keluarganya untuk memenuhi kebutuhan hidup. Mayoritas responden di atas usia 40 tahun. Pendidikan terakhir responden terbanyak adalah tingkat lulusan Sekolah Dasar, sebanyak 7 orang (54\%). Mereka berstatus sebagai petani. Dua orang (15 $\%$ adalah lulusan SLTA/sederajat, merupakan lembaga pemasaran malai Pandanwangi serta tingkat lulusan sarjana (S1) berjumlah 5 orang (38\%).

\section{Dinamika Harga Malai Pandanwangi di Desa Tegallega Kecamatan Warungkondang Kabupaten Cianjur}

Penentuan harga malai

Pandanwangi ditentukan oleh lembaga pemasaran (pemilik pabrik malai). Petani biasa menjual padi Pandanwangi ke tengkulak dalam bentuk malai. Alasan padi Pandanwangi harus dijual dalam bentuk malai adalah untuk menjaga keawetan gabah, kualitas dan ketahanan aroma malai Pandanwangi agar tidak berkurang Harga malai Pandanwangi pada Tahun 2013 berkisar Rp. 4.200,00 - Rp. $5.200,00 / \mathrm{kg}$. Tahun 2014 harga beli naik berkisar Rp. 5000,00 - Rp. 5.500,00. Berdasarkan pengalaman petani, harga tertinggi padi Pandanwangi terjadi pada Bulan Mei - Juni. Sebaliknya pada musim panen pada Bulan November - Desember 
harga padi menurun. Hal ini diduga karena pada bulan Mei - Juni merupakan bulan kering, sehingga tanaman tidak mudah rebah dan menghasilkan padi yang berisi penuh. Selain itu, proses pengeringan atau penjemuran lebih cepat sehingga dapat menghasilkan padi (malai) yang berkualitas baik (Harisman, 2017). Dari Tahun 2014 sampai Tahun 2017 harga malai tidak mengalami kenaikan yaitu berkisar Rp. 5.000,00 - Rp. 5.500,00 / kg.

Kelompok Tani Mekar Tani, Kelompok Tani Karya Barokah dan Kelompok Tani Sari Tani menerima harga malai berkisar antara Rp. 5000,00 - Rp. $5.500,00$ dan langsung dibayarkan tunai oleh tengkulak (lembaga pemasaran). Begitupun dengan Koperasi Mitra Parahiyangan membeli malai dari petani di Desa Tegallega berkisar antara Rp. 5.000,00 - Rp. 5.500,00 dan langsung dibayarkan tunai. Berbeda halnya dengan petani lainnya yang secara mandiri memilih satu lembaga pemasaran yang dapat membeli malai dengan harga lebih tinggi yaitu berkisar Rp.5.500,00 Rp.7.000,00. Harga beli lebih tinggi karena tidak dibayarkan secara langsung melainkan ditunda hingga penjualan malai habis terjual. Karena kebanyakan petani ingin mendapatkan uang secara langsung dari hasil malai yang dibeli tengkulak untuk modal usahatani selanjutnya, sekaligus untuk memenuhi kebutuhan sehari - hari.

$$
\text { Perbandingan harga malai }
$$

Pandanwangi dengan gabah VUN pada Tahun 2013 sekitar Rp. 1.100,00 dan pada Tahun 2014 - 2017 selisihnya adalah Rp.1.000. Perbandingan harga malai Pandanwangi dengan gabah VUN yang tidak berbeda jauh ini, menyebabkan penurunan budidaya padi Pandanwangi. Kebanyakan petani desa Tegallega beralih menanam padi VUN dibandingkan padi Pandanwangi.

Penawaran dan Permintaan Malai
Pandanwangi di Desa Tegallega
Kecamatan
Kabupaten Cianjur
Penawarangkondang
Pealah jumlah barang yang tersedia dan dijual oleh produsen. Ketersediaan malai Pandanwangi, dilihat dari kemampuan petani dalam menanam dan menghasilkan malai Pandanwangi. Dari hasil penelitian secara umum, selama 5 tahun terakhir petani di Desa Tegallega menghasilkan malai Pandanwangi yang cenderung tetap. Karena luas lahan yang dibudidayakan padi Pandanwangi tidak berubah. Penawaran petani terhadap malai Pandanwangi di Desa Tegallega pada Tahun 2013 - Tahun 2017 dapat dilihat pada tabel 1. 
Tabel 1. Penawaran Petani Terhadap Malai Pandanwangi Per Tahun Di Desa Tegallega

Tahun 2013- 2017.

\begin{tabular}{|c|c|c|}
\hline Tahun & Produsen (Kelompok Tani) & Volume Penawaran (kg) \\
\hline \multirow[t]{4}{*}{2013} & 1. Karya Barokah & 60.000 \\
\hline & 2. Mekar Tani & 32.000 \\
\hline & 3. Sari Tani & 40.000 \\
\hline & 4. Petani (non-kelompok tani) & 30.000 \\
\hline \multirow[t]{4}{*}{2014} & 1. Karya Barokah & 60.000 \\
\hline & 2. Mekar Tani & 32.000 \\
\hline & 3. Sari Tani & 40.000 \\
\hline & 4. Petani (non-kelompok tani) & 30.000 \\
\hline \multirow[t]{4}{*}{2015} & 1. Karya Barokah & 60.000 \\
\hline & 2. Karya Tani & 32.000 \\
\hline & 3. Sari Tani & 40.000 \\
\hline & 4. Petani (non-kelompok tani) & 30.000 \\
\hline \multirow[t]{4}{*}{2016} & 1. Karya Barokah & 60.000 \\
\hline & 2. Mekar Tani & 32.000 \\
\hline & 3. Sari Tani & 40.000 \\
\hline & 4. Petani (non-kelompok tani) & 30.000 \\
\hline \multirow[t]{4}{*}{2017} & 1. Karya Barokah & 60.000 \\
\hline & 2. Mekar Tani & 32.000 \\
\hline & 3. Sari Tani & 40.000 \\
\hline & 4. Petani (non-kelompok tani) & 30.000 \\
\hline
\end{tabular}

Sumber : data primer (data olahan), 2018.

Terdapat 5 lembaga pemasaran beras Pandanwangi yang membeli malai dari Desa Tegallega. Untuk permintaan malai yang dapat disediakan oleh petani dan permintaan kosumen terhadap beras Pandanwangi lebih jelasnya dapat dilihat pada tabel 2.

Table 2. Permintaan Malai dan Beras Pandanwangi Per Tahun Di Desa Tegallega.

\begin{tabular}{lllcc}
\hline $\begin{array}{l}\mathbf{N} \\
\mathbf{0}\end{array}$ & Kelompok Tani & Lembaga Pemasaran & $\begin{array}{c}\text { Permintaan } \\
\text { Malai } \\
\mathbf{( k g )}\end{array}$ & $\begin{array}{c}\text { Permintaan Beras } \\
\mathbf{( k g )}\end{array}$ \\
\hline $\mathbf{1 .}$ & Karya Barokah & Johan & $\mathbf{5 8 . 0 0 0}$ & $\mathbf{2 6 . 1 0 0}$ \\
\hline $\mathbf{2 .}$ & Mekar Tani & Kustana & 32.000 & 14.400 \\
\hline $\mathbf{3 .}$ & Sari Tani & Johan & $\mathbf{4 0 . 0 0 0}$ & $\mathbf{1 8 . 0 0 0}$ \\
\hline $\mathbf{4 .}$ & $\begin{array}{l}\text { Petani lain (non } \\
\text { aktif) }\end{array}$ & Yahya & 20.000 & 9.000 \\
\hline $\mathbf{5 .}$ & $\begin{array}{l}\text { Petani Lain (non } \\
\text { aktif) }\end{array}$ & $\begin{array}{l}\text { Koperasi Mitra } \\
\text { Parahiyangan }\end{array}$ & 10.000 & 4.500 \\
\hline $\mathbf{6 .}$ & $\begin{array}{l}\text { Ketua Karya } \\
\text { Barokah }\end{array}$ & Yusuf & 2.000 & 900 \\
\hline \multicolumn{1}{c}{ Total } & & $\mathbf{1 6 2 . 0 0 0}$ & $\mathbf{7 2 . 9 0 0}$
\end{tabular}

Sumber : data primer (data olahan), 2018.

Struktur Pasar Malai Pandanwangi di Desa Tegallega Kecamatan Warungkondang Kabupaten Cianjur Untuk mengukur atau menentukan struktur pasar, pertama kali yang dilakukan adalah mengumpulkan data tentang pangsa pasar atau market share dalam persen (Anindita R dan Baladina N, 2017). Secara deskriptif, struktur pasar

Analisis Struktur Pasar Malai Pandanwangi Di Desa Tegallega Kecamatan Warungkondang Kabupaten Cianjur beras Pandanwangi di Desa Tegallega menjelaskan jumlah pelaku pasar dan hambatan keluar masuk pasar.

Perhitungan jumlah konsentrasi rasio $(\mathrm{Kr})$ malai Pandanwangi yang dibeli lembaga pemasaran di Desa Tegallega dapat dilihat pada tabel 3 . 
Tabel 3. Perhitungan Jumlah Konsentrasi Rasio (Kr) Malai Pandanwangi yang Dibeli Lembaga Pemasaran di Desa Tegallega.

Lembaga Pemasaran Jumlah Malai yang Dibeli Lembaga Konsentrasi Rasio (Kr)

\begin{tabular}{lrr} 
& Pemasaran (kg) & $\mathbf{( \% )}$ \\
\hline Johan & 98.000 & 60,50 \\
\hline Kustana & 32.000 & 19,76 \\
\hline Yahya & 20.000 & 12,34 \\
\hline Koperasi Mitra \\
Parahiyangan & 10.000 & 6,17 \\
\hline Yusuf & & 1,23 \\
\hline Total & 2.000 & $\mathbf{1 0 0}$ \\
\hline
\end{tabular}

Sumber : data primer (data olahan), 2018.

Tabel 3 persentase jumlah malai Pandanwangi yang dibeli oleh 5 orang lembaga pemasaran dari semua produsen malai Pandanwangi di Desa Tegallega adalah $100 \%$. Hal tersebut menunjukkan pada kriteria empat pedagang memiliki nilai $\mathrm{Kr}$ minimal 80\%, maka pasar tersebut dikatakan sebagai pasar oligopsoni konsentrasi tinggi. Pasar Oligopsoni, merupakan pasar yang terdiri atas beberapa orang pembeli (lebih dari dua) dan banyak penjual (produsen).

Perhitungan pangsa pasar lembaga pemasaran terhadap malai Pandanwangi per Tahun di Desa Tegallega dapat dilihat pada tabel 4.

Tabel 4. Perhitungan Pangsa Pasar Lembaga Pemasaran terhadap Malai Pandanwangi per tahun di Desa Tegallega.

\begin{tabular}{lrr}
\hline \multicolumn{1}{c}{ Lembaga Pemasaran } & $\begin{array}{c}\text { Hasil Pembelian Malai } \\
\text { Pandanwangi (kg) }\end{array}$ & Pangsa Pasar (\%) \\
\hline Johan & 98.000 & 60,50 \\
\hline Kustana & 32.000 & 19,76 \\
\hline Yahya & 20.000 & 12,34 \\
\hline $\begin{array}{l}\text { Koperasi Mitra } \\
\text { Parahiyangan }\end{array}$ & 10.000 & 6,17 \\
\hline Yusuf & & 1,23 \\
\hline Total & 2.000 & $\mathbf{1 0 0}$ \\
\hline
\end{tabular}

Sumber : data primer (data olahan), 2018.

Tabel 4 total perhitungan pangsa pasar lembaga pemasaran malai Pandanwangi dari Desa Tegallega adalah $100 \%$. Posisi pangsa pasar lembaga pemasaran di Desa Tegallega merupakan pasar oligopoli ketat, karena masuk dalam kriteria penggabungan 4 pedagang yang memiliki 60 - 100\% pangsa pasar. Namun pasar ini, di dominasi oleh satu lembaga pemasaran, yaitu : Johan sebanyak 60,50
$\%$ dibandingkan lembaga pemasaran yang lain.

Pangsa pembelian malai Pandanwangi yang dibeli oleh 5 lembaga pemasaran di Desa Tegallega telah diketahui pada tabel 4.13. Jadi perhitungan analisis IH pada struktur malai Pandanwangi di Desa Tegallega dapat dilihat pada tabel 5 . 
Tabel 5. Perhitungan Analisis Indeks Herfindhal (IH) Pada Struktur Malai Pandanwangi di Desa Tegallega.

\begin{tabular}{|c|c|c|c|}
\hline $\begin{array}{l}\text { Lembaga } \\
\text { Pemasaran }\end{array}$ & $\begin{array}{l}\text { Hasil Pembelian Malai } \\
\text { Pandanwangi (kg) }\end{array}$ & Pangsa Pasar (\%) & $\mathbf{I H}\left(\mathbf{S}^{2}\right)$ \\
\hline Johan & 98.000 & 60,50 & \\
\hline Kustana & 32.000 & 19,76 & \\
\hline Yahya & 20.000 & 12,34 & \\
\hline $\begin{array}{l}\text { Koperasi Mitra } \\
\text { Parahiyangan }\end{array}$ & 10.000 & 6,17 & \\
\hline Yusuf & 2.000 & 1,23 & \\
\hline Total & 162.000 & 100 & \\
\hline
\end{tabular}

Sumber : data primer (data olahan), 2018.

Tabel 5 total perhitungan analisis IH pada struktur pasar malai Pandanwangi di Desa Tegallega, sebanyak 0,4181 . Hal ini menunjukkan pada kriteria $0<\mathrm{IH}<1$ maka bentuk struktur pasar malai Pandanwangi dari Desa Tegallega adalah pasar oligopsoni. Pasar oligopsoni merupakan pasar yang terdiri atas beberapa orang pembeli (lembaga pemasaran) dan banyak penjual (produsen/petani). Dalam pasar ini peran lembaga pemasaran lebih dominan. Karena lembaga pemasaran memiliki kekuatan sebagai pedagang dan pada faktanya jumlah produsen (petani) lebih banyak dibandingan lembaga pemasaran.

\section{KESIMPULAN DAN SARAN}

\section{Kesimpulan}

1. Dinamika harga malai relative tidak mengalami perubahan dari Tahun 2013 - 2017. Tahun 2013 harga malai pandanwangi per $\mathrm{kg}$ berkisar $\mathrm{Rp}$ 4.200-Rp 5.200 Harga malai tidak mengalami perubahan dari Tahun 2014 - Tahun 2017, yakni berkisar Rp 5.000 - Rp 5.500 per kg. Selisih harga malai Pandanwangi dengan gabah VUN sekitar Rp. 1000,00.

2. Penawaran malai Pandanwangi di Desa Tegallega selama 5 tahun terakhir cenderung tetap, sebanyak $162.000 \mathrm{~kg}$ per tahun, didapat dari budidaya padi Pandanwangi kurang lebih seluas 20 ha. Karena luas lahan tidak bertambah maka penawaran pun tidak mengalami perubahan.

Analisis Struktur Pasar Malai Pandanwangi Di Desa Tegallega Kecamatan Warungkondang Kabupaten Cianjur
Total permintaan malai Pandanwangi di Desa Tegallega sebanyak 162.000 kg per tahun, sebetulnya permintaan meningkat tetapi tidak dapat dipenuhi oleh petani di desa tersebut.

3. Struktur malai Pandanwangi di Desa Tegallega berdasarkan data hasil analisis didapat pada tabel 4.13 menunjukkan pada pasar oligopsoni. Pasar oligopsoni merupakan pasar yang terdiri atas beberapa orang pembeli (lembaga pemasaran) dan banyak penjual (produsen/petani). Namun pangsa pasar yang paling dominan dikuasai oleh Johan sebanyak 60,50 \% dibandingkan lembaga pemasaran yang lainnya.

\section{Saran}

1. Bagi Pemerintah terkait, terus membina dan memantau perkembangan usahatani padi Pandanwangi di Kabupaten Cianjur. Memberikan bantuan permodalan bagi produsen (petani) agar mampu memproduksi lebih banyak. Menolong petani untuk memasarkan secara langsung pada konsumen agar pendapatan petani meningkat. Menjembatani pertemuan antara petani dengan lembaga pemasaran, agar lembaga pemasaran tidak memonopoli harga.

2. Bagi Penyuluh, terus memberikan pengetahuan tentang pasar dan pemasaran.

3. Bagi para petani atau kelompok tani di Desa Tegallega : 
a. Ketua harus sering memotivasi anggota agar tetap berusahatani pada padi Pandanwangi.

b. Lebih terbuka terhadap sumber informasi dari luar terutama tentang pangsa dan struktur pasar.

c. Merangkul petani muda sebagai generasi penerus karena banyak petani yang sudah masuk ke dalam katagori usia tidak produktif.

d. Melakukan pengarsipan data usahatani sebagai bahan penentuan komoditas dan pola tanam.

e. Antar kelompok tani hendaknnya bekerjasama agar memiliki posisi penting dalam penentuan harga malai.

f. Menerapkan teknologi terutama pertanian organik untuk meningkatkan hasil produktivitas.

4. Bagi mahasiswa, dapat melakukan penelitian sejenis di desa lain atau tempat diperluas sehingga memperoleh gambaran tentang struktur pasar malai Pandanwangi.

\section{DAFTAR PUSTAKA}

Anindita, R dan Baladina, N. 2017. Pemasaran Produk Pertanian. Edisi I. Yogyakarta :ANDI. 55281

Aviny, EY, Nurmalina, R dan Najmi Anniro. 2009. Analisis Sistem Tataniaga Beras Pandanwangi Di Kecamatan Warungkondang, Kabupaten Cianjur Provinsi Jawa Barat. Jurnal Agribisnis dan Ekonomi Pertanian. Vol. 3. No 2.

Hadikusumah, KH. 2015. Deskripsi Pengambilan Keputusan dalam Berusahatani Padi Pandanwangi di Kalangan Petani (Studi Kasus pada Petani Lapisan Atas dan Lapisan Bawah Berdasarkan Luas
Lahan Desa Bunikasih

Kecamatan Warungkondang

Kabupaten

Cianjur).journal.uinsgd.ac.id/inde

x.php/istek/article/download/24 $6 / 260$.

Harisman, K. 2017. Deskripsi Pengambilan Keputusan Dalam Berusahatani Padi Pandanwangi (Oriza sativa L) di Kalangan Petani Cianjur. Tersedia di https://mpra.unimuenchen.de.

Lungan, R. 2006. Aplikasi Statistika dan Hitung Peluang. Yogyakarta: Graha Ilmu.

Saragih, AE. 2014. Analisis Sistem Pemasaran Beras Ciherang di Kecamatan Cibeber Kabupaten Cianjur. Skripsi. Fakultas Ekonomi Dan Manajemen. Institut Pertanian Bogor.

Suryana, A. 2012. Dinamika Kebijakan Harga Gabah dan Beras Dalam Mendukung Ketahanan Pangan Nasional.

https://www.google.co.id/url?sa 三t\&source $=$ web\&rct $=j \& u r l=h t t$ ps://media.neliti.com/media/pu blications/30887-ID-dinamikakebijakan-harga-gabah-dan-berasdalam-mendukung-ketahananpangan-nasion.pdf.

Sugiyono. 2011. Metode Penelitian Pendidikan Pendekatan Kuantitatif, Kualitatif, dan R\&D. Bandung: Alfabeta.

2012. Metodologi Penelitian Kuantitatif Kualitatif dan $\mathrm{R} \ll D$. Bandung:Alfabeta.

Widia,W, Dewi, N dan Jum'atri Yusri. 2015. Analisis Scp (Structure, Conduct and Performance) Pasar Ojol Di Kecamatan Kampar Kiri Kabupaten Kampar. Tersedia di https://media.neliti.com/media/ $\mathrm{pu}$ 